\title{
HUBUNGAN ANTARA BERAT BAYI LAHIR RENDAH DENGAN TUMBUH KEMBANG ANAK USIA DINI
}

\author{
Annaas Budi Setyawan \\ Sekolah Tinggi Ilmu Kesehatan Muhammadiyah Samarinda \\ Email: sutini.mgt@gmail.com
}

Article received: 07 May 2017 Review process: 20 Agustus 2017

Article published: 30 September 2017

\begin{abstract}
ABSTRAK
Pertumbuhan dan perkembangan mengalami peningkatan yang pesat pada usia dini, yaitu dari 0 sampai 5 tahun. Masa ini sering juga disebut sebagai fase "Golden Age" atau masa yang sangat penting untuk memperhatikan tumbuh kembang anak secara cermat agar sedini mungkin dapat terdeteksi apabila terjadi kelainan. Tujuan penelitian ini adalah untuk mengetahui hubungan antara berat bayi rendah dengan tumbuh kembang anak usia pra sekolah (4-5 tahun) di TK Kusuma Dewi Handil Baru Darat Tahun 2016. Jenis penelitian ini adalah deskriptif korealsi dengan menggunakan pendekatan cross sectional. Pengambilan sampel dilakukan dengan purposive random sampling, dengan jumlah sampel sebanyak 54 responden. Teknik pengumpulan data menggunakan kuesioner penelitian dan DDST. Pengolahan dan analisa data menggunakan analisa univariat dengan distribusi frekuensi dan analisa bivariat dengan uji statistik Chi Square dengan taraf signifikan $\alpha$ 0,05 dan CI $95 \%$. Sebagian besar responden tidak memiliki riwayat bayi rendah sebanyak 45 anak $(83,3 \%)$ dan memiliki riwayat bayi rendah sebanyak 9 anak (16,7\%). sebagian besar responden tumbuh sesuai dengan tumbuh kembang sebanyak 48 anak $(88,9 \%)$ dan tidak sesuai sebanyak 6 anak $(11,1 \%)$. Hasil uji statistik diperoleh nilai $p=0,561$, maka dapat disimpulkan tidak ada hubungan antara bayi lahir rendah dengan tumbuh kembang siswa di TK Kusuma Dewi Handil Baru Darat.
\end{abstract}

Kata kunci : Berat lahir rendah, Tumbuh kembang

\section{PENDAHULUAN}

Pertumbuhan dan perkembangan mengalami peningkatan yang pesat pada usia dini, yaitu dari 0 sampai 5 tahun. Masa ini sering juga disebut sebagai fase "Golden Age" atau masa yang sangat penting untuk memperhatikan tumbuh kembang anak secara cermat agar sedini mungkin dapat terdeteksi apabila terjadi kelainan. Selain itu, penanganan kelainan yang sesuai pada masa golden age dapat meminimalisir kelainan pertumbuhan dan perkembangan anak sehingga kelaianan yang bersifat permanen dapat dicegah. Periode emas dapat diwujudkan apabila pada masa ini bayi dan anak memperoleh asupan gizi yang sesuai untuk 
tumbuh kembang optimal, sebaliknya apabila bayi dan anak pada masa ini tidak memperoleh makanan sesuai kebutuhan gizinya, maka periode emas akan berubah menjadi periode kritis yang akan mengganggu tumbuh kembang bayi dan anak, baik pada saat ini maupun masa selanjutnya (Nutrisiani, 2010).

Pencapaian derajat kesehatan yang tinggi bagi anak adalah sebagai satu bagian dari system pelayanan kesehatan di keluarga. Keluarga sebagai suatu kehidupan yang konstan dan individu mendukung, menghargai dan meningkatkan kekuatan dan kompetensi dalam memberikan asuhan terhadap anak, sedangkan prinsip keperawatan anak harus berfokus pada anak dan keluarga, untuk memenuhi kebutuhan anak dan kelurga. Kebutuhan dasar seorang anak adalah asah (kebutuhan akan stimulasi mental dini), asih (kebutuhan emosianal), dan asuh (kebutuhan biomedis). Ketiga kebutuhan dasar anak tersebut seharusnya terpenuhi sehingga anak akan tumbuh sesuai dengan tugas perkembangannya. Karena bila anak mengalam keterlambatan pada salah satu tugas perkembangan, maka akan mempengaruhi tugas perkembangan berikutnya. Hal ini akan menyebabkan gangguan psikologis, yaitu kurangnya kepercayaan diri pada diri anak(Wong, 2009).

Faktor predisposisi yang menyebabkan terjadinya persalinan dengan BBLR meliputi faktor ibu, faktor plasenta, faktor janin, dan faktor yang tidak diketahui. Faktor ibu meliputi karakteristik ibu dan komplikasi kehamilan. Karakteristik ibu adalah umur, jumlah paritas, umur kehamilan, dan riwayat BBLR sebelumnya. komplikasi kehamilan meliputi: hamil dengan hidramnion, hamil ganda, perdarahan antepartum, dan preeklampsi/eklampsi. Faktor janin adalah cacat bawaan dan infeksi dalam rahim Faktor plasenta adalah penyakit vaskuler (Markum, 2008).

Badan kesehatan dunia (WHO) bekerja sama dengan March of Dimes, lembaga sosial dari Amerika Serikat yang memiliki misi mencegah Bayi BBLR dan cacat melaporkan setiap tahun diperkirakan 13 juta bayi BBLR di seluruh dunia dan satu juta bayi meninggal dunia. Kelahiran bayi BBLR ini paling banyak terjadi di negara miskin dan berkembang, terutama di Afrika dan Asia. Jumlah tertinggi ada di Afrika dan diikuti dengan Amerika Utara. Tingginya prevelansi berat badan lahir rendah (BBLR) umumnya karena dari ibu hamil yang kurang gizi. Akibatnya, pertumbuhan janin terganggu sehingga berisiko lahir dengan berat di bawah 2.500 gram. Di Indonesia, diperkirakan prevelansi BBLR mencapai 7-14 persen, bahkan pada 
beberapa kabupaten mencapai 16 persen. Padahal, berdasarkan simposium Low Birth Weight di Dhaka, Banglades, tingkat indikasi BBLR lebih dari 15 persen dimaknai adanya masalah kesehatan masyarakat yang penting dan serius (Depkes, 2009).

Di Indonesia Kejadian BBLR bervariasi, menurut analisa Sumber Data Kesehatan Indonesia (SDKI) 2009 kejadian BBLR sebesar 6\%. Kejadian BBLR berdasarkan provinsi bervariasi dengan rentang $2 \%-15,1 \%$ di mana yang terendah adalah provinsi Sumatera Utara dan yang tertinggi adalah Sulawesi Selatan. Hasil yang diperoleh melalui data indikator kesehatan yang berasal dari pelayanan kesehatan, BBLR pada provinsi Kalimantan Timur masih rendah yakni berkisar antara $0,17 \%$ tahun 2001 dan $0,19 \%$ tahun 2002, kemudian tahun 2003 (1,79\%), tahun 2004 (1,31\%). Pada tahun 2009 untuk BBLR di Kaltim adalah 1,54\% dari jumlah penduduk (Profil Kalimantan Timur 2011).

Periode prasekolah (usia 4 sampai 6 tahun) adalah usia mempersiapkan anak untuk perubahan gaya hidupnya yang paling bermakana yaitu usia masuk sekolah. Tantangantantangan perkembangan dari periode sebelumnya diakhiri dalam lingkungan social yang luas dan dibentuk kembali oleh pertambahan bahasa yang rumit. Sebagai contoh adalah tantangan pengaturan diri sendiri dalam menghadapi kemungkinan dorongan yang besar. Masalah ini, pada awal masa pertumbuhan,muncul kembali seperti anak menghadapi tempat bermain yang ramai atau suatu ruang kelas prasekolah. Ketegangan antara pertumbuhan perasaan otonomi anak dan keterbatasan internal maupun eksternal, menentukan pusat dinamis usia ini. Keberhasilan pencapaian tingkat pertumbuhan dan perkembangan sebelumnya sangat penting bagi anak prasekolah untuk memperhalus tugas-tugas yang telah mereka kuasai. Banyak pendidikan pra sekolah yang biasanya dipilih oleh orang tua, misalnya play group (Kelompok bermain) khusus untuk anak-anak usia 3-4 tahun dan TK (Taman Kanak-Kanak) khusus untuk usia 4-5 tahun (Wong, 2009).

TK Kusuma Dewi adalah salah satu TK yang berada pada Kecamatan Handil Baru Darat Kabupaten Kutai Kartanegara. TK ini menampung siswa sebanyak 58 anak. Dari survey awal yang dilakukan peneliti pada tanggal 07 mei 2016 jam 09.00 wita dengan metode wawancara kepada 10 orang tua siswa, di dapatkan bahwa 3 di antaranya memiliki anak dengan riwayat berat badan lahir rendah yaitu kurang dari 2000 gr dan mereka pun merasa bahwa anak-anak mereka yang memiliki riwayat berat badan lahir rendah tidak memiliki 
pertumbuhan dan perkembangan yang sama dengan teman-teman sebaya mereka yang lain, seperti dari tinggi badan dan juga kecepatan berhitung. Didapatkan pula informasi dari guru, bahwa 3 siswa yang bersangkutan memang selalu kurang dalam hal berhitung dibanding dengan teman-teman mereka yang lain.

\section{METODE PENELITIAN}

Penelitian ini menggunakan rancangan deskriptif korelasional yang bertujuan untuk melihat hubungan antara bayi lahir rendah dengan tumbuh kembang anak pra sekolah (4-5 tahun) di TK Dewi Handil Baru Darat Tahun 2016. Bayi lahir rendah sebagai variabel independen dan tumbuh kembang anak pra sekolah (4-5 tahun) sebagai variabel dependen. Dalam rancangan ini digunakan pendekatan cross sectional. Populasi penelitian ini adalah siswa TK Kusuma Dewi Handil Baru Darat sebanyak 58 anak. Waktu pelaksanaan penelitian ini adalah selama 2 minggu, Tempat pelaksanaan penelitian yaitu di TK Kusuma Dewi Handil Baru Darat. Instrumen penelitian yang digunakan yaitu kuesioner untuk mengetahui riwayat lahir berat rendah yang diisi oleh orang tua anak dan tes skiring DDST untuk mengetahui tentang tumbuh kembang anak. Uji analisis bivariat yang digunakan adalah uji chi square, sehingga dapat diketahui ada atau tidaknya hubungan yang bermakna secara statistik dengan menggunakan program komputer dan derajat kemaknaan 95\%. Apabila nilai $(p<0,05)$ maka Ho ditolak dan Ha (hipotesa penelitian) diterima, yang berarti ada hubungan antara variabel bebas dan variabel terikat, sedangkan bila nilai $(\mathrm{p}>0,05)$ maka Ho diterima dan Ha (Hipotesa penelitian) ditolak yang berarti tidak ada hubungan antara variabel bebas dengan variabel terikat (Nursalam, 2012).

\section{HASIL PENELITIAN}

\section{1) Varibel Univariat}

Tabel 1 . Responden berdasarkan riwayat lahir berat rendah $<2500 \mathrm{gr}$ dan tumbuh kembang anak di TK Kusuma Dewi Handil Baru Darat.

\begin{tabular}{ccc}
\hline Riwayat lahir & Frekuensi & $\mathbf{( \% )}$ \\
\hline Tidak $(>2500$ gr $)$ & 45 & 83,3 \\
\hline Iya $(\leq 2500$ gr $)$ & 9 & 16,7 \\
\hline Jumlah & $\mathbf{5 4}$ & $\mathbf{1 0 0}$ \\
\hline Tumbuh Kembang Anak & Frekuensi & $\mathbf{( \% )}$ \\
\hline Normal & 48 & 88,9 \\
\hline Abnormal & 6 & 11,1 \\
\hline Jumlah & $\mathbf{5 4}$ & $\mathbf{1 0 0}$
\end{tabular}


Sumber: Data Primer 2016

Dari tabel 1 diperoleh hasil bahwa sebagian besar responden tidak memiliki riwayat bayi rendah sebanyak 45 anak $(83,3 \%)$ dan memiliki riwayat bayi rendah sebanyak 9 anak $(16,7 \%)$. Selain itu diperoleh hasil bahwa sebagian besar responden tumbuh norma dengan tumbuh kembang sebanyak 48 anak $(88,9 \%)$ dan abnormal sebanyak 6 anak $(11,1 \%)$.

\section{2) Variabel Bivariat}

Tabel 2 Analisa hubungan antara riwayat bayi lahir rendah dengan tumbuh kembang anak di TK Kusuma Dewi Handil Baru Darat Tahun 2016

\begin{tabular}{|c|c|c|c|c|c|c|c|c|}
\hline \multirow{3}{*}{$\begin{array}{c}\text { Variabel } \\
\begin{array}{c}\text { Riwayat Bayi Lahir } \\
\text { Rendah }\end{array} \\
\end{array}$} & \multicolumn{4}{|c|}{ Tumbuh Kembang Anak } & \multirow{2}{*}{\multicolumn{2}{|c|}{ Total }} & \multirow{3}{*}{$\begin{array}{c}\text { OR } \\
95 \% \text { CI }\end{array}$} & \multirow{3}{*}{$\begin{array}{c}P \\
\text { Value }\end{array}$} \\
\hline & \multicolumn{2}{|c|}{ Normal } & \multicolumn{2}{|c|}{ Abnormal } & & & & \\
\hline & $\mathrm{N}$ & $\%$ & $\mathrm{~N}$ & $\%$ & $\mathrm{~N}$ & $\%$ & & \\
\hline Tidak (>2500 gr) & 39 & 81,2 & 6 & 100 & 45 & 83,3 & & \\
\hline Iya ( $(\leq 2500 g r)$ & 9 & 18,8 & 0 & 0 & 9 & 16,7 & $\begin{array}{c}0,8 \\
(0,7-0,9)\end{array}$ & 0,561 \\
\hline Jumlah & 48 & 100 & 6 & 100 & 54 & 100 & & \\
\hline
\end{tabular}

Sumber: Data Primer 2016

Dari tabel 2 diperoleh dari 48 anak di peroleh bahwa 39 anak (81,2\%) tidak memiliki riwayat bayi lahir rendah dan tumbuh kembang yang sesuai dengan usianya, sedangkan 9 anak lainnya $(18,8 \%)$ ada riwayat bayi lahir rendah tetapi memiliki tumbuh kembang yang sesuai dengan usianya dan dari 6 anak di dapatkan 6 anak (100\%) tidak memiliki riwayat lahir bayi rendah dan tidak sesuai dengan tumbuh kembang anak dan Selain itu dari hasil analisa bivariat didapatkan pula odd ratio 95\% CI 0,8 yang artinya bahwa tidak ada riwayat bayi lahir rendah berpotensi 0,8 kali tumbuh kembang anak tidak sesuai dengan usianya. Selain itu didapat pula P Value sebesar 0,561 yang artinya tidak ada hubungan antara bayi lahir rendah dengan tumbuh kembang anak di TK Kusuma Dewi Handil Darat Tahun 2016.

\section{PEMBAHASAN}

Berdasarkan hasil penelitian analisa univariat bahwa sebagian besar responden tidak memiliki riwayat bayi rendah sebanyak 45 anak $(83,3 \%)$ dan memiliki riwayat berat bayi lahir rendah sebanyak 9 anak (16,7\%). Menurut Setyowati (2010), Faktor predisposisi yang menyebabkan terjadinya persalinan dengan BBLR meliputi faktor ibu, faktor plasenta, faktor janin, dan faktor yang tidak diketahui. Faktor ibu meliputi karakteristik ibu dan komplikasi kehamilan. Karakteristik ibu adalah umur, jumlah paritas, umur kehamilan, dan riwayat 
BBLR sebelumnya. komplikasi kehamilan meliputi: hamil dengan hidramnion, hamil ganda, perdarahan antepartum, dan preeklampsi/eklampsi. Faktor janin adalah cacat bawaan dan infeksi dalam rahim Faktor plasenta adalah penyakit vaskuler. Dari hasil penelitian di dapatkan ada 9 anak $(16,7 \%)$ yang memilikii riwayat bayi lahir rendah, menurut hemat peneliti hal ini disebabkan karena salah satu wilayah di Handil Baru masih percaya dengan dukun sehingga untuk pemeriksaan kehamilan tidak rutin di puskesmas sehingga menyebabkan permasalahan kehamilan tidak terdeteksi oleh pelayanan kesehatan.

Bayi BBLR adalah empat puluh kali lebih mungkin meninggal dalam empat minggu pertama mereka hidup daripada berat kelahiran normal bayi. Bayi BBLR juga tiga kali lebih mungkin dari bayi berat badan lahir normal untuk memiliki komplikasi dan perkembangan saraf kongenital kelainan. Kursus neonatal pada bayi BBLR lahir prematur ( $<32$ minggu) didominasi oleh komplikasi disebabkan oleh ketidakdewasaan misalnya anatomi dan fisiologis lahir asfiksia, hipotermia, gangguan pernapasan karena tertunda alveolar pembersihan air dan surfaktan kekurangan, tertunda adaptasi peredaran darah setelah melahirkan dengan paru hipertensi, hipotensi sistemik dan tertunda penutupan shunt janin. Ketidakdewasaan dan mengurangi toko substrat menjelaskan tingginya prevalensi hipo/hiperglikemia, penyakit kuning dan koagulopati belum matang (Hidayat, 2010).

Menurut analisis bahwa sebagian besar responden tidak memiliki riwayat bayi lahir rendah, hal ini di sebabkan karena orang tua rutin untuk memeriksakan kandungan ke tenaga kesehatan, dukungan dari keluarga juga sangat berperan untuk mencegah kelahiran bayi lahir rendah. Biasanya bila tenaga kesehatan menemukan adanya indikasi kejadian kelahiran bayi lahir rendah, akan di rujuk ke rumah sakit yang memiliki fasilitas lebih baik. Oleh sebab itu peneliti menyarankan kepada pimpinan pelayanan kesehatan agar memberikan seminar ataupun pelatihan khusus kepada petugas kesehatan dasar mengenai penanganan pertama bayi lahir rendah sehingga bayi lahir rendah mendapatkan penanganan pertama yang baik, selain itu perlunya kader posyandu mengadakan penyuluhan kesehatan mengenai pentingnya pemeriksaan kehamilan di pelayanan kesehatan terdekat (Damanik, 2009).

Berdasarkan hasil penelitian di dapatkan bahwa sebagian besar responden tumbuh normal dengan tumbuh kembang sebanyak 48 anak (88,9\%) dan abnormal sebanyak 6 anak (11,1\%). Pada usia 4 tahun di dapatkan anak yang sesuai dengan tumbuh kembangnya 
sebanyak 20 anak $(37,0 \%)$ dan usia 5 tahun yang sesuai dengan tumbuh kembangnya sebanyak 28 anak (51.9\%). Menurut Soetjiningsih (2012) secara umum terdapat dua faktor yang mempengaruhi tumbuh kembang anak yaitu faktor genetik (instrinsik) dan faktor lingkungan (ekstrinsik). Faktor genetik merupakan modal dasar dalam mencapai hasil akhir proses tumbuh kembang anak. Faktor ini adalah bawaan yang normal dan patologis, jenis kelamin, suku bangsa / bahasa, gangguan pertumbuhan di negara maju lebih sering diakibatkan oleh faktor ini, sedangkan di negara yang sedang berkembang, gangguan pertumbuhan selain di akibatkan oleh faktor genetik juga faktor lingkungan yang kurang memadai untuk tumbuh kembang anak yang optimal. Faktor genetik patologis yang sering terjadi salah satunya adalah berat bayi lahir rendah (BBLR). Menurut analisis ada beberapa anak yang tidak sesuai dengan tumbuh kembang anak seusia mereka, ada lima anak yang tidak dapat melakukan satu parameter dari empat parameter yang di berikan sehingga masuk ke dalam kategori tidak sesuai dengan tumbuh kembang dalam penelitian ini. Sebagian besar responden tumbuh sesuai dengan usia mereka yaitu dengan parameter berdiri dengan satu kaki (gerakan kasar), dapat mengancingkan baju (gerakan halus), dapat bercerita sederhana (bahasa bicara dan kecerdasan), dapat mencuci tangan sendiri (bergaul dan mandiri). Oleh sebab itu peneliti menyarankan kepada orang tua dan pihak sekolah untuk secara rutin melakukan pemeriksaan tumbuh kembang anak dan selalu berkoordinasi dengan pihak tenaga kesehatan apabila di temukan kejanggalan pada masa tumbuh kembang anak agar dapat teratasi secara tepat (Zaveira, 2008).

Menstimulasi tumbuh kembang anak usia TK tidak terlepas dari karakternya yang berada pada masa bermain; dan tentu saja dengan tidak mengenyampingkan gaya belajar yang dimiliki anak. Melalui bermain anak dapat berkembang baik aspek maupun kecerdasannya. Dalam satu kegiatan bermain, ada beberapa aspek ataupun beberapa kecerdasan anak yang berkembang. Menurut Kurikulum 2004 (KBK), aspek yang dimaksud adalah aspek kemampuan dasar (bahasa, daya pikir, daya cipta, fisik/jasmani, dan keterampilan) dan aspek pembiasaan (perilaku, moral, pancasila, dan disiplin). Kecerdasan yang dimaksud adalah kecerdasan jamak atau kecerdasan majemuk (multiple intelligences) yang terdiri dari kecerdasan linguistik, kecerdasan matematis-logis, kecerdasan ruang-visual, kecerdasan 
kinestetik-badani, kecerdasan musikal, kecerdasan interpersonal, kecerdasan intrapersonal, kecerdasan lingkungan (natural), dan kecerdasan eksistensial (Hidayat, 2010).

Dari analisa statistik uji Bivariat di dapatkan bahwa hasil $\mathrm{P}$ value 0, $561>0,05$ yang artinya tidak ada hubungan antara riwayat bayi lahir rendah dengan tumbuh kembang anak di TK Kusuma Dewi Handil Baru Darat. Hasil ini sesuai dengan penelitian Huda (2004) Berdasarkan hasil tersebut, bahwa tidak ada hubungan antara riwayat bayi BBLR dan anak yang sedang tumbuh dan pengembangan. Penelitian ini dapat digunakan untuk memotivasi orang dalam meningkatkan perawatan anak, terutama yang memiliki sejarah yang dari BBLR untuk mengoptimalkan pertumbuhan dan perkembangan anak. Analisis keeratan hubungan antara dua variabel didapatkan $\mathrm{OR}=0,8$ bahwa tidak ada riwayat bayi lahir rendah berpotensi 0,8 kali tumbuh kembang anak tidak sesuai dengan usianya. Nilai confidence Interval dari tabel diatas (95\% CI :0,7-0,9), memilki jarak yang cukup dekat ini berarti semakin dekat interval maka hubunganya pun semakin kuat dikarenakan masih ada beberapa faktor lain yang mungkin berpengaruh dalam tumbuh kembang anak dan riwayat lahir berat rendah tidak terlalu signifikan berpengaruh terhadap tumbuh kembang anak. Banyak faktor yang mempengaruhi tumbuh kembang anak, tidak hanya pada riwayat bayi lahir rendah saja, menurut Nutrisiani (2010) faktor-faktor yang mempengaruhi pertumbuhan, yaitu heredo konstitusional (tergantung ras, genetik, jenis kelamin, dan kelainan bawaan), faktor hormonal (insulin, tiroid, hormon sex dan steroid), serta faktor lingkungan selama dan sesudah lahir (gizi, trauma, sosio-ekonomi, iklim, aktivitas fisik, penyakit, dll). Hasil wawancara dengan para orang tua yang menyekolahkan anaknya di TK. Dewi sebagian besar memiliki kemampuan ekonomi yang cukup baik sehingga mampu memberikan asupan gizi yang baik bagi anaknya. Asupan gizi sangat berperan dalam tumbuh kembang anak. Selain itu pemberian stimulasi tumbuh kembang anak dilakukan oleh ibu dan ayah yang merupakan orang terdekat dengan anak, pengganti/ pengasuh anak, anggota keluarga lain dan kelompok masyarakat di lingkungan rumah tangga masing-masing dan dalam kehidupan sehari-hari dapat mempengaruhi tumbuh kembang anak yang optimal (Chamidah, 2009).

\section{KESIMPULAN}

1. Hasil penelitian analisa univariat yaitu sebagian besar responden tidak memiliki riwayat bayi rendah sebanyak 45 anak $(83,3 \%)$ dan memiliki riwayat bayi rendah sebanyak 9 anak 
(16,7\%), selain itu sebagian besar responden tumbuh sesuai dengan tumbuh kembang sebanyak 48 anak $(88,9 \%)$ dan tidak sesuai sebanyak 6 anak $(11,1 \%)$.

2. Hasil uji statistik diperoleh nilai $p=0,561$, maka dapat disimpulkan tidak ada hubungan antara bayi lahir rendah dengan tumbuh kembang siswa di TK Kusuma Dewi Handil Baru Darat 2016.

\section{DAFTAR PUSTAKA}

AB Setyawan, ES Lestari, W Winarto . 2016. Ekstrak Daun Kejibeling Meningkatkan Fagositosis Dan Roi Makrofag Pada Mencit Diinfeksi Staphylococcus aureus. Jurnal Kesehatan masyarakat 11 (2) 173-177, 2016

Chamidah A.N., 2009. Deteksi Dini Gangguan Pertumbuhan dan Perkebangan Anak. Jurnal Pendidikan Khusus. 5(2) : 84, 89, 92

Dinkes Kaltim. 2011. Profil Kesehatan Kalimantan Timur 2011. Samarinda

Depkes RI, 2009. Pedoman Pelaksanaan Stimulasi, Deteksi, dan Intervensi Dini Tumbuh Kembang Anak di Tingkat Pelayanan Kesehatan Dasar. Jakarta : Depkes RI.

Damanik S.M., 2009. Buku Ajar Neonatologi. Jakarta : Badan Penerbit IDAI

Hidayat A.A., 2010. Pengantar Ilmu Kesehatan Anak untuk Pendidikan Kebidanan. Jakarta : salemba Medika

Nutrisiani. 2010. Pertumbuhan dan perkembangan anak. Jakarta: Salemba.

Nursalam, 2012. Konsep dan Penerapan Metodelogi Penelitian Ilmu Keperawatan. Jakarta : EGC

Markum AH. 2008. Ilmu Kesehatan Anak. Jakarta. Fakultas Kedokteran Universitas Indonesia.

Soetjiningsih. 2012. Tumbuh Kembang Anak. EGC, Jakarta.

Wong. 2009. Pedoman Klinis Keperawatan Pediatrik. EGC. Jakarta.

Zaveira, Ferdinand. 2008. Mengenali dan Memahami Tumbuh Kembang Anak. Jogjakarta : Katahati 